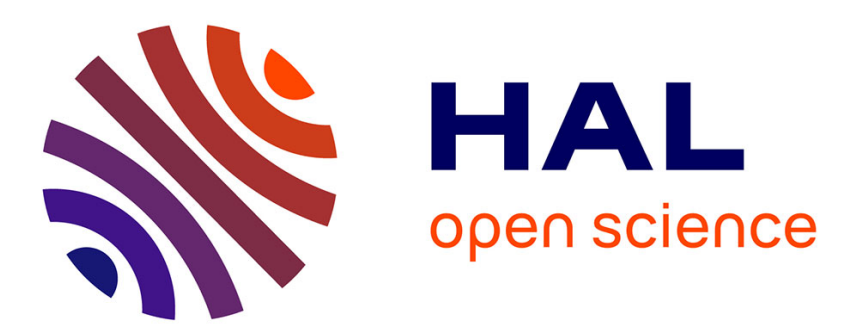

\title{
Challenges of Heavy Load Logistics in Global Maritime Supply Chains
}

\author{
Thorsten Wuest, Jakub Mak-Dadanski, Björn Kaczmarek, Klaus-Dieter \\ Thoben
}

\section{- To cite this version:}

Thorsten Wuest, Jakub Mak-Dadanski, Björn Kaczmarek, Klaus-Dieter Thoben. Challenges of Heavy Load Logistics in Global Maritime Supply Chains. IFIP International Conference on Advances in Production Management Systems (APMS), Sep 2015, Tokyo, Japan. pp.175-182, 10.1007/978-3-31922759-7_20 . hal-01431092

\section{HAL Id: hal-01431092 \\ https://hal.inria.fr/hal-01431092}

Submitted on 10 Jan 2017

HAL is a multi-disciplinary open access archive for the deposit and dissemination of scientific research documents, whether they are published or not. The documents may come from teaching and research institutions in France or abroad, or from public or private research centers.
L'archive ouverte pluridisciplinaire HAL, est destinée au dépôt et à la diffusion de documents scientifiques de niveau recherche, publiés ou non, émanant des établissements d'enseignement et de recherche français ou étrangers, des laboratoires publics ou privés. 


\title{
Challenges of heavy load logistics in global maritime supply chains
}

\author{
Thorsten Wuest ${ }^{1}$, Jakub Mak-Dadanski ${ }^{2}$, Björn Kaczmarek ${ }^{2}$, \\ Klaus-Dieter Thoben ${ }^{2,3}$ \\ ${ }^{1}$ Industrial and Management Systems Engineering, Benjamin M. Statler College of En- \\ gineering and Mineral Resources, West Virginia University, Morgantown, WV, USA \\ thwuest@mail . wvu . edu \\ ${ }^{2}$ ICT Applications for Production, BIBA - Bremer Institut für Produktion und Logistik, \\ Bremen, Germany \\ \{dad, kaz, tho\} @biba.uni-bremen.de \\ ${ }^{3}$ Integrated Product Development, Faculty of Production Engineering, University of \\ Bremen, Bremen, Germany \\ tho@biba.uni-bremen.de
}

\begin{abstract}
Global trade is steadily increasing and among the vast amount of traded goods are not only standardized cargo but also a selection of large and bulky heavy loads. Heavy loads often require special attention when it comes to identifying suitable shipping and loading means within logistic processes. In this paper the challenges of heavy load logistics are identified and discussed. Whereas the main goal of the paper is to highlight the challenges and problems in this domain, a possible solution approach within the Design for $\mathrm{X}$ framework is introduced briefly.
\end{abstract}

Keywords: heavy loads; logistics; supply chains; Design for X (DfX); DfT; DfL

\section{Introduction}

In the growing world economy, the supply chains of many companies are strained to ship the needed goods and cargo across vast distances in a timely and safe manner. Maritime commerce, the shipment of goods using maritime vessels, is a steady growing, and important part of German economy, as it generates significant economic benefits to ports and their host's cities. The traded goods are not only standardized cargo, which can be shipped with the help of container vessels, but also a selection of large and bulky heavy loads. This research paper aims to highlight the issues of heavy load transportation in maritime shipping.

In the next section, the different transportation modes of global supply chains are introduced with a special focus on non-standardized cargo (heavy loads). Following this theoretical foundation, the existing challenges and problems of heavy loads when it comes to logistics processes, especially maritime logistic processes, are discussed. After the challenges are pointed out, a possible solution approach within the DfX 
framework is presented in section three, before the paper is summarized in section four where a brief conclusion and an outlook on further research is given.

\section{State of the art}

In this section, first the different transportation types of cargo transport are elaborated. Following, the focus is set on maritime logistics (shipping) processes including an introduction to the currently available ship types. Finally, non-standardized cargo, also known as heavy loads or heavy lifts, is presented in more detail. Heavy loads are in the focus of this paper as they represent very specific challenges which have yet to be overcome by global supply chain practitioners.

Cargo transport can be divided into three main modes of transportation: air, sea and land transport (see Fig. 1). This publication concentrates on the maritime mode of non-standard sized cargo transport. In the contrary to other cargo types, bulk (e.g., grain, bauxite ore) and general cargo (e.g., TEU containers), the vessels for heavy loads are mostly not standardized and the shipment of oversize goods is costly and time consuming. Through a thorough examination of the shipment of exemplary nonstandard sized goods, in this case wind turbines and cranes, this paper will attempt to provide an overview of challenges and possible approaches to overcoming the issues of heavy load maritime transport.

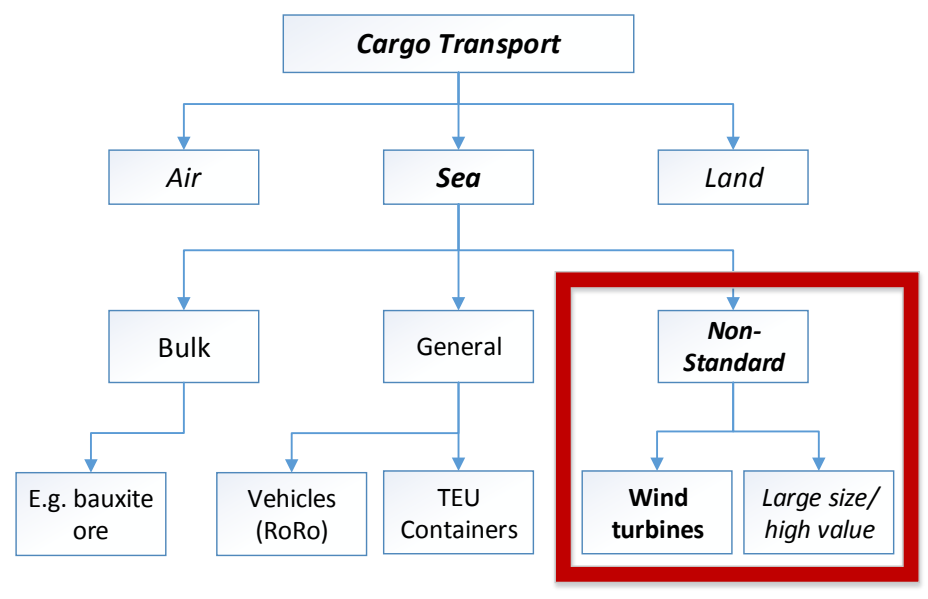

Fig. 1: Transportation types

The following subsection will provide a brief overview of the cargo transport over sea, the general vessels, and introduce in detail the issues of oversized cargo in maritime shipping.

\subsection{Modes of Transportation in Maritime Shipping}

As of today, the design of maritime vessels has been oriented into accommodating the craft to the to be transported product (e.g., cars, containers, iron ore, oil). It is best 
reflected in the various (standard) types of vessels in the shipbuilding industry (see Fig. 2), e.g. in dry cargo ships, which are comprised i.a. of tramps, cargo liners, container vessels \& ro-ro (roll on/ roll off) ships [1]. Among the types of cargo transported via dry cargo ships are general cargo, bulk cargo, vehicles and special heavy cargo. Regarding the size of ships, another factor influences the build with the capability to 'fit' through certain passages like the Panama Canal, hence 'Panamax' / 'New Panamax' class vessels.



Fig. 2: Ship types (based on [1] [16])

General cargo is a vital component of the maritime commerce, generating significant economic benefits to ports and their host cities. The transport of general cargo has been dominated through the trend towards containerization since its inception in 1966 [2]. The 'break-bulk' freight, individual parcels or pieces, is being containerized in the dimensions of a Twenty-foot Equivalent Unit (TEU), generally referred to as standard container [3]. This trend led to a steady and substantial increase in the container vessels size in recent years, with largest ships operated by Maersk, which can carry a reported 13,500 TEU. Ro-ro ships, especially designed for the transport of vehicles, are usually fitted with various ramps for loading through the shell doors of the ship. Cargo is carried in vehicles and trailers or in unitized form loaded by forkload and other trucks [1], [4].

Another important type of freight are the wide ranging bulk commodities, including i.a. coal, grain, bauxite ore, and shipments of products such as packaged steel and timber. A general arrangement of a typical bulk carrier shows a clear deck with machinery aft, and large hatches with steel covers, designed to facilitate rapid loading and discharge of the cargo [1], [4].

Additionally to bulk and standard cargo, there is also the non-standard sized cargo, e.g. wind turbine components. Non-standard sized cargo has distinct properties, often a relatively large size, high value, and sensitivity, that doesn't allow for standard methods of transportation. 
In this publication the focus is placed upon the non-standard sized cargo as such didn't receive as much attention with regard to transportability compared to the others yet. In the following subsection, this will be illustrated in greater detail.

\subsection{Non-standard sized cargo}

Non-standard sized cargo, often described as Heavy loads, is nowadays a rapid growing part of cargo shipping. Heavy loads include goods like wind turbine parts, tunneling equipment, plants, heavy cranes, project cargo etc. These type of goods distinguish themselves with very special characteristics regarding the weight, sensibility and geometry, and are often very high-value products. As heavy loads have very big dimensions, and are transported either in parts or whole (depending on customer requirements), the properties of the load, including the distribution of the cargo mass, it's center of gravity, inertia, the transverse moments, the torsion, the vibration, the stability of the carrier, and the cargo geometry itself, are very important while shipping heavy loads, and have to be addressed in early stages of the shipping process [5]. The following points summarize information crucial to the physical challenges associated with the transport of heavy loads $[6,7,8,9]$ :

- Environmental criteria (e.g. motion response during environmental events)

- $\quad$ Proper transport vessel due to mass and dimensions

- $\quad$ Stability during transport and during on-loading/off-loading

- $\quad$ Extreme transport force

- Cargo footprint

- $\quad$ Sensitivity for damage

- $\quad$ Cribbing and fastening arrangements (lashing, chains, slings, hooks etc.)

- $\quad$ Transport \& Insurance costs

These factors directly relate to the transport and insurance costs. Not only the shipper, but also the designer of the heavy load cargo, has to be aware of these factors to ensure proper and safe transport. As already mentioned, heavy loads include, e.g., wind turbines or cranes. For years the vessels of choice for the shipment of wind turbines and cranes have been project cargo, and semi-submersible heavy load ships. Other vessels, used for the transport of heavy loads, are dock ships, module and crane carriers, geared project cargo ships and lo-lo (load on/load off) ships. Companies like, e.g., ZPMC (Shanghai Zhenhua Heavy Industries) adapt older bulk carriers into nonsubmersible heavy load ships lacking any superstructures in the main loading area and equipped with sideway funnels, both useful characteristics in the shipment of heavy loads [10].

\section{Design for $\mathrm{X}$ as a possible solution approach}

The above listed issues of heavy load transport are met with several approaches: The first approach is to adapt and customize the vessels to meet the needs of heavy load transportation. We have seen this approach in the adapted open deck carriers of 
ZPMC, where the vessels are modified into non-submersible heavy load ships. This is not only costly but also time intensive, as the redesign and development of special vessels presents a major investment on the shipper.

Another approach to the presented issues could lie in the redesign, or inclusion of design recommendations into the design of heavy load products. The Design for $\mathrm{X}$ (DfX) methodology, and its extensions, i.a. Design for Logistics (DfL) and Design for Transportability (DfT) supply this publication with a framework for the abovementioned design recommendations.

DfX, or "Design for Excellence", describes design guidelines in many different areas of product development. Each design guideline addresses a specific design issue, caused by or affecting a specific characteristic of a product. Therefore the ' $\mathrm{X}$ ' can stand for e.g., Manufacturability/Manufacturing (DfM), Assembly (DfA), Reliability, Logistics, or Transportability. DfX guidelines have proven to effectively reduce costs, time-to-market, number of assembly operations and product assembly time. The application of DfX requires manufacturing engineers and designers to work together rather than individually [11].

\subsection{Design for $\mathrm{X}$ with Supply Chain / Logistics focus}

DfX also includes Design for Logistics (DfL). DfL aims to improve capabilities in the supply chain management to control logistic processes, and the overall customer service levels, as well as, to cut operational costs. Some of its other goals can be summarized in increasing logistics efficiency, and gaining /or sustaining competitive advantage. The DfL approach tries to reach these goals by improving the transportability and usability of the to-be-designed product. Products should be designed in a way, to provide sustained logistics support capabilities for its planned product life cycle $[12,13]$. This can be reflected in, e.g., modularization to realize the product in parts [14].

A practical example of integration of DfL in industry is to add certain restrictions into the CAD design system or database of the designer, which would feature the logistic requirements. It is essential to connect the early design and manufacturing with the later logistic processes, as the engineers and designers are often not aware of or do not focus on necessary logistic requirements. As in DfX, it's important to connect the expertise of inter-disciplinary experts, like engineers and logistics professionals [12].

An important extension of DfL is "Design for Transportability" (DfT). According to Dowlatshahi, transportation costs represent the single most important aspect of the logistics costs, and as such DfT is able to realize economies of scale and thus reduce prices and costs. Next to costs reduction, one of the main goals of DfT is a product design which allows for safe handling and transportation, free from hazards and dangers to the personnel involved. This includes reliable and timely transit time (speed of delivery) in the transport of the goods. Dowlatshahi lists a number of design characteristics that affect transportability to an extent [12]:

- $\quad$ Physical properties (width, height, length, center of gravity, etc.)

- Dynamic limitations (acceleration, vibration, deflection, leaking, etc.) 
- $\quad$ Environmental limitations (temperature, pressure, humidity, etc.)

- Hazardous effects (radiation, explosives, electrostatic, personnel safety, etc.)

To reach these goals, logistic considerations such as the type of goods, size and length of shipment and mode of transportation, should be known to the designer in the early design stages (see Fig. 3), as well as to develop a standard in which the products have a compatible size with the given transport facilities. If the design guidelines can satisfy these requirements, it would be possible to reduce the transportation costs, thus improving the competitive advantage of the producing firm [12].

As seen in Figure 3, the extension of DfX considerations into DfL and DfT does not exclude the need for DfM or DFA. Whereas the DfL and DfT guidelines concern the overall supply chain (logistics and transportation), the DfA and DfM relate to the company and the process levels, and thus require more detailed information. DfL and DfT are relevant from the concept development stage, as the proposed product architecture can reveal how the transportability of the product will be affected [14].

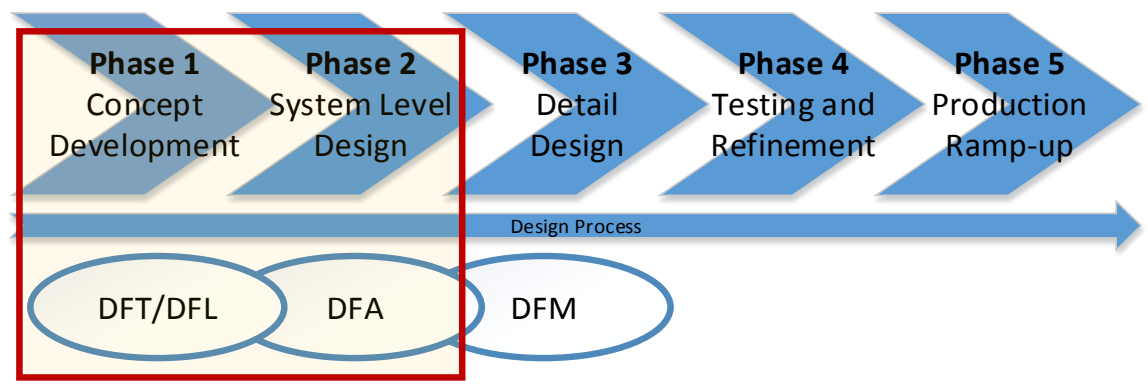

Fig. 3: Sequential DfX with DfT/DfL timing [14]

\subsection{Discussion}

While outlining the framework for the DfL/DfT design guidelines for improved shipment of heavy loads, there are three points, which have always to be considered [14]: DfL and / or DfT cannot be performed without knowledge of the products shipping process; it must be performed with a specific objective in mind (e.g. reducing costs); a measure of transportability must be defined (e.g. transportation time). With these points in mind, the following table can be seen as a starting point to DfL and DfT in maritime transport for designers of heavy load products. It provides an overview of issues the designer has to take into consideration [15]:

Tab. 1: Issues before and after the shipment of heavy loads

\begin{tabular}{|l|ll|}
\hline & Before Transport (Loading) & \multicolumn{2}{c|}{ After Transport (Unloading) } \\
\hline - Departure port conditions & - & Destination port conditions \\
- Vessel properties & - Vessel properties \\
- Assembly state of the cargo & - Assembly state of the cargo \\
- Load safety during loading & - & Load safety during unloading \\
\hline
\end{tabular}


- $\quad$ Suitable loading equipment and $\quad$ - Suitable loading equipment and skilled staff skilled staff

It has to be noted that this discussion is rather high level. In order to practically apply this or similar approaches in practice, a more detailed and thorough investigation, including physical design elements has to be considered.

\section{Conclusion and outlook}

Shipping of heavy loads is increasing steadily, however, it bears many challenges, e.g., regarding the loading and unloading but also the choice of the right equipment. As heavy loads are mostly handled as individual, unique loads, the logistics cost and effort is rather high. To this point this is dealt with by specialized brokers who are able to book a suitable vessel and ensure the appropriate loading equipment is available. However, often the solution is not optimized and inefficient. In some cases, like e.g., wind energy platforms/blades, customized vessels specifically designed for a certain task exist. It has to be noted, that this exception is not in the focus of this paper as it presents a different set of challenges and they are still not the norm. In this paper the authors investigating existing challenges in this area to provide the reader a better understanding and a basis for the development of possible solution approaches.

In this paper, even though the focus was on providing a better understanding of the challenges and problems at hand when it comes to heavy load logistics, DfX methods were suggested as one possible way of tackling the identified issues.

Proper use, extension and adaption of DfL and DfT guidelines in early design stages seems to offer potential for a more integrated management of heavy load logistics. The DfL and DfT guidelines may not only optimize the product design to enhance the 'shippability'; the amount of transport equipment, often specialized, may be reduced, and the safety of the load may be increased at the same time, thus reducing the transport and insurance costs.

As DfL and DfT support the overall logistics and transportability capabilities of the product design, further expansion of the DfX guidelines, regarding the special aspects of maritime shipping, have to be recommended for further research. This 'Design for Shipping' (DfS) could include the DfL and DfT aspects, while taking closer examination of the special issues of maritime shipping and heavy loads handling at the docks. The authors are currently working on developing a DfS set of guidelines to support the appropriate consideration of the logistics challenges in early product development phases including a mathematical model in order to generalize the findings. The results will be published in an appropriate archival journal within the next year.

\section{Acknowledgement}

This work is based on multiple discussions with practitioners in the field of maritime shipping, heavy loads logistics and harbor professionals. The authors would like to extend their gratitude to the persons involved and thank them for their time and valu- 
able input. Furthermore, the authors would like to extend their gratitude to the reviewers for their valuable feedback, which helped to improve the manuscript.

\section{References}

1. Eyres, D. J., Bruce, G. J.: "Ship Construction”, 7. Edition, ButterwortHeinemann, pp.17-33 (2012)

2. Vigarié, A.: "From break-bulk to containers: the transformation of general cargo handling and trade", GeoJournal, Vol. 48, pp. 3-7 (1999)

3. Notteboom, T. E.: "Container Shipping and Ports: An Overview", Review of Network Economics, Vol.3, Issue 2, pp. 86-106 (2004)

4. Brinkmann, A.: „Seehäfen: Planung und Entwurf“, Springer, Berlin Heidelberg New York, pp.65-66 (2005)

5. Galor, A., Galor, W., \& Kryzan, A.: "Oversize Cargo in Sea Transport in South Baltic Region" Transcomp-XIV International Conference Computer Systems Aided Science, Industry and Transport, pp. 1-8 (2010)

6. Van Hoorn, F. (2008): Heavy-Load Transport Ships - Overview of Existing Fleet and Future Development", Proceedings of the Marine Operations Specialty Symposium, Singapore, pp.1-9 (2008)

7. Franke, B.: „Logistik in der Windkraft - Sicherheit in jeder Lage“, BPUVZ, Vol.11, pp.506-509 (2010)

8. Hermann, S.: "Offshore Wind Farms: Analysis of Transport and Installation Costs”, ECN Wind Energy, pp. 1-122 (2002)

9. Lau, R.: "Transportation of wind turbines as cargo - a loss prevention article", SKULD , pp. 1-6 (2013)

10. ZPMC: "For Sale by Horizon Lines, LLC", http://www.zpmc.com/sales.php?act=product1

11. Kuo, T.-C., Huang, S.H., Zhang, H.-C.: "Design for manufacture and design for ' $\mathrm{X}$ ': concepts, applications, and perspectives", Computers \& Industrial Engineering, Vol. 41:3, pp. 241-260 (2001)

12. Dowlatshahi, S.: "The role of logistics in concurrent engineering", International Journal of Production Economics, Vol.44, pp.189-199 (1996)

13. Schulze, S.: "Effiziente Logistik Durch Kooperation in Der Produktentwicklung", Automobillogistik: Stand und Zukunftstrends, pp.179-192 (2013)

14. Gubi, E.: "Design for Logistics", Center for Industrial Production, Aalborg University, Denmark, pp. 47-61 (2005)

15. Van Hoorn, F., Wijsmuller Transport B. V.: "The Dry Transport of the Green Canyon Tension Leg Wellhead Platform by a Semisubmersible Heavy-Loading Ship", 22nd Offshore Technoligy Conference, pp. 1-18 (1990)

16. BIGLOAD: "Happy Star", http://www.bigloadshipping.com/assets/data/vesselspecs/datasheet $\% 20 \mathrm{Happy} \% 2$ 0Star_nb.pdf 